\title{
Dry Needling for Patients With Neck Pain: Protocol of a Randomized Clinical Trial
}

Eric Robert Gattie ${ }^{1}$, PT; Joshua A Cleland ${ }^{2}$, PT, PhD; Suzanne J Snodgrass ${ }^{3}$, PT, PhD

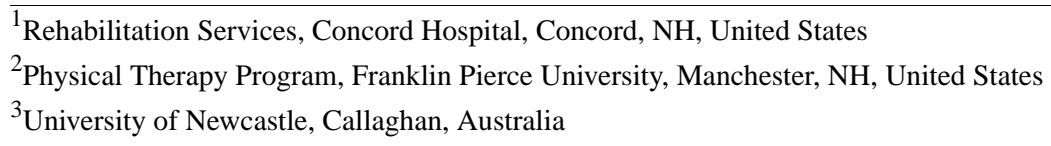

Corresponding Author:

Eric Robert Gattie, PT

Rehabilitation Services

Concord Hospital

264 Pleasant Street

Concord, NH, 03301

United States

Phone: 16038604729

Email: ericgattie@gmail.com

\begin{abstract}
Background: Neck pain is a costly and common problem. Current treatments are not adequately effective for a large proportion of patients who continue to experience recurrent pain. Therefore, new treatment strategies should be investigated in an attempt to reduce the disability and high costs associated with neck pain. Dry needling is a technique in which a fine needle is used to penetrate the skin, subcutaneous tissues, and muscle with the intent to mechanically disrupt tissue without the use of an anesthetic. Dry needling is emerging as a treatment modality that is widely used clinically to address a variety of musculoskeletal conditions. Recent studies of dry needling in mechanical neck pain suggest potential benefits, but do not utilize methods typical to clinical practice and lack long-term follow-up. Therefore, a clinical trial with realistic treatment time frames and methods consistent with clinical practice is needed to examine the effectiveness of dry needling on reducing pain and enhancing function in patients presenting to physical therapy with mechanical neck pain.
\end{abstract}

Objective: The aim of this trial will be to examine the short- and long-term effectiveness of dry needling delivered by a physical therapist on pain, disability, and patient-perceived improvements in patients with mechanical neck pain.

Methods: We will conduct a randomized, double-blind, placebo-controlled trial in accordance with the CONSORT guidelines. A total of 76 patients over the age of 18 with acute or chronic mechanical neck pain resulting from postural dysfunction, trauma, or insidious onset who are referred to physical therapy will be enrolled after meeting the eligibility criteria. Subjects will be excluded if they have previous history of surgery, whiplash in the last 6 weeks, nerve root compression, red flags, or contraindications to dry needling or manual therapy. Participants will be randomized to receive (1) dry needling, manual therapy, and exercise or (2) sham dry needling, manual therapy, and exercise. Participants will receive seven physical therapy treatments lasting 45 minutes each over a maximum of 4 weeks. The primary outcome will be disability as measured by the Neck Disability Index. Secondary outcomes include the following: pain, patient-perceived improvement, patient expectations, and successful blinding to the needling intervention. Outcome measures will be assessed at 4 weeks, 6 months, and 12 months by an assessor who is blind to the group allocation of the participants to determine the short- and long-term treatment effects. We will examine the primary aim with a two-way, repeated-measures analysis of variance with treatment group as the between-subjects variable and time as the within-subjects variable. The hypothesis of interest will be the two-way group by time interaction. An a priori alpha level of .05 will be used for all analyses.

Results: Recruitment is currently underway and is expected to be completed by the end of 2017. Data collection for long-term outcomes will occur throughout 2017 and 2018. Data analysis, preparation, and publication submission is expected to occur throughout the final three quarters of 2018.

Conclusions: The successful completion of this trial will provide evidence to demonstrate whether dry needling is effective for the management of mechanical neck pain when used in a combined treatment approach, as is the common clinical practice. 
Trial Registration: ClinicalTrials.gov NCT02731014; https://clinicaltrials.gov/ct2/show/NCT02731014 (Archived by WebCite at http://www.webcitation.org/6ujZgbhsq)

(JMIR Res Protoc 2017;6(11):e227) doi: 10.2196/resprot.7980

\section{KEYWORDS}

neck pain; dry needling; physical therapy

\section{Introduction}

Neck pain is common, with $30 \%-50 \%$ of the population afflicted in a given year [1]. Symptoms of neck pain persist longer than 12 months in $37 \%$ of patients [2]. Neck pain is ranked fourth highest out of all 291 conditions studied in the Global Burden of Disease 2010 study measured by years lived with disability [3]. In the United States, estimated increases in expenditures for patients with spine pain have increased 65\% from 1997 to 2005 [4]. Patients with neck pain account for $10 \%-20 \%$ of all patients seen in outpatient physical therapy $[5,6]$.

Commonly, physical therapists utilize patient education, exercise, mobilization, manipulation, massage, and electrophysical modalities when treating patients with mechanical neck pain. Yet the most recent Cochrane reviews on patient education [7], exercise [8], and manual therapy (ie, joint mobilization [9] and massage [10]) find a lack of high-quality evidence to support these interventions independently. There is some evidence that multi-modal physical therapy treatment consisting of a combination of exercise and mobilization/manipulation seems to be more effective than either intervention alone [11].

Dry needling has emerged as a treatment modality that is widely used in the clinical environment to address a variety of musculoskeletal conditions including neck pain [12-14]. Dry needling is growing in popularity despite a lack of clinical trials examining its effectiveness, likely due to the ease of applying dry needling in a clinical setting $[15,16]$. Dry needling is a technique in which a fine needle is used to penetrate the skin, subcutaneous tissues, and muscle with the intent to mechanically disrupt tissue without the use of an anesthetic [17].

Most commonly, dry needling targets myofascial trigger points (MTrPs), which are described as localized hypersensitive spots in a palpable taut band of muscle [18-28]. These hyperirritable spots can be classified as active MTrPs when they produce spontaneous pain and, when palpated, reproduce a patient's familiar pain. Latent MTrPs do not produce spontaneous pain and are only painful upon palpation [29]. Many studies have shown that MTrPs are prevalent in patients with chronic neck pain [30-34]. It has been reported that MTrPs in the neck and shoulder commonly result in limited range of motion in the neck, neck pain, headache, and dizziness $[28,33,35]$.

There have been five recent studies examining dry needling performed by a physical therapist for patients with neck pain. Four of the trials examined the short-term effectiveness of dry needling: three in chronic mechanical neck pain $[21,24,28]$ and one in acute mechanical neck pain [23]. The results of these studies demonstrated that dry needling decreases pain intensity and increases pain pressure threshold in the short term; the longest follow-up was 4 weeks. One recent trial examined the long-term effectiveness of dry needling, which was performed on patients with chronic nonspecific neck pain [36]. At 6-month follow-up, the dry needling and passive stretching group demonstrated significant and clinically relevant improvements in pain, disability, and range of motion when compared to passive stretching alone. These results suggest that dry needling warrants further investigation for the treatment of neck pain.

Recent systematic reviews suggest that dry needling can be recommended in the short and medium term to reduce neck and shoulder pain [37] and for musculoskeletal pain [38]. Yet those reviews concluded that there was limited evidence to support dry needling's effectiveness in the long term for reducing pain or improving function, especially when compared to other physical therapy interventions. Both authors recommended further studies with adequate sample sizes to examine dry needling effectiveness in both the short and long term on reducing pain and improving function.

The majority of the studies included in the recent reviews compared dry needling to control, sham, or to another intervention directly. Not only is this not consistent with how dry needling is commonly used clinically by physical therapists, but emerging evidence suggests that dry needling, when performed in combination with other interventions, may be more effective at reducing lower back pain than when performed alone [39]. This suggests that dry needling, when combined with other interventions (ie, multi-modal treatment), may result in an improved treatment effect when compared to dry needling performed in isolation.

The majority of existing studies lack adequate sample sizes, only collect short-term outcomes, frequently examine dry needling as a stand-alone intervention, and only treat one muscle for one to two sessions, which is not consistent with how dry needling is commonly performed clinically. Typically, clinicians will perform an examination to locate active and latent MTrPs and needle numerous active trigger points in a single session. They may then dry needle the patient over many sessions to achieve optimal effects. With the high prevalence of neck pain and its contribution to prolonged disability in patients, it is essential to identify optimal treatment approaches $[1-3,5,6,40,41]$. Therefore, the aim of this randomized clinical trial is to examine the long-term effects of a combination of manual therapy, exercises, and dry needling to the cervicothoracic region on pain and disability in individuals with acute or chronic mechanical neck pain resulting from postural dysfunction, trauma, or insidious onset who are referred to physical therapy.

We hypothesize that patients who receive dry needling, manual therapy, and exercise will achieve greater reductions in pain 
and disability in the short term (ie, 4 weeks) and long term (ie, 6 and 12 months) compared to those who receive sham dry needling, manual therapy, and exercise.

\section{Methods}

\section{Design}

We will conduct a randomized, double-blind, placebo-controlled trial according to the CONSORT guidelines (see Figure 1)
$[42,43]$. Approval by both the Institutional Review Board at Concord Hospital (Concord, NH, USA), where the trial will be performed, and the University of Newcastle Human Research Ethics Committee (Callaghan, Australia), where the primary author (ERG) is currently enrolled as a $\mathrm{PhD}$ candidate, have been obtained. Consecutive subjects presenting to Concord Hospital physical therapy clinics (Concord, NH, USA) and Franciscan St. Francis Health physical therapy clinics (Indianapolis, IN, USA) with mechanical neck pain will be screened for eligibility criteria.

Figure 1. Flowchart of the study trial.

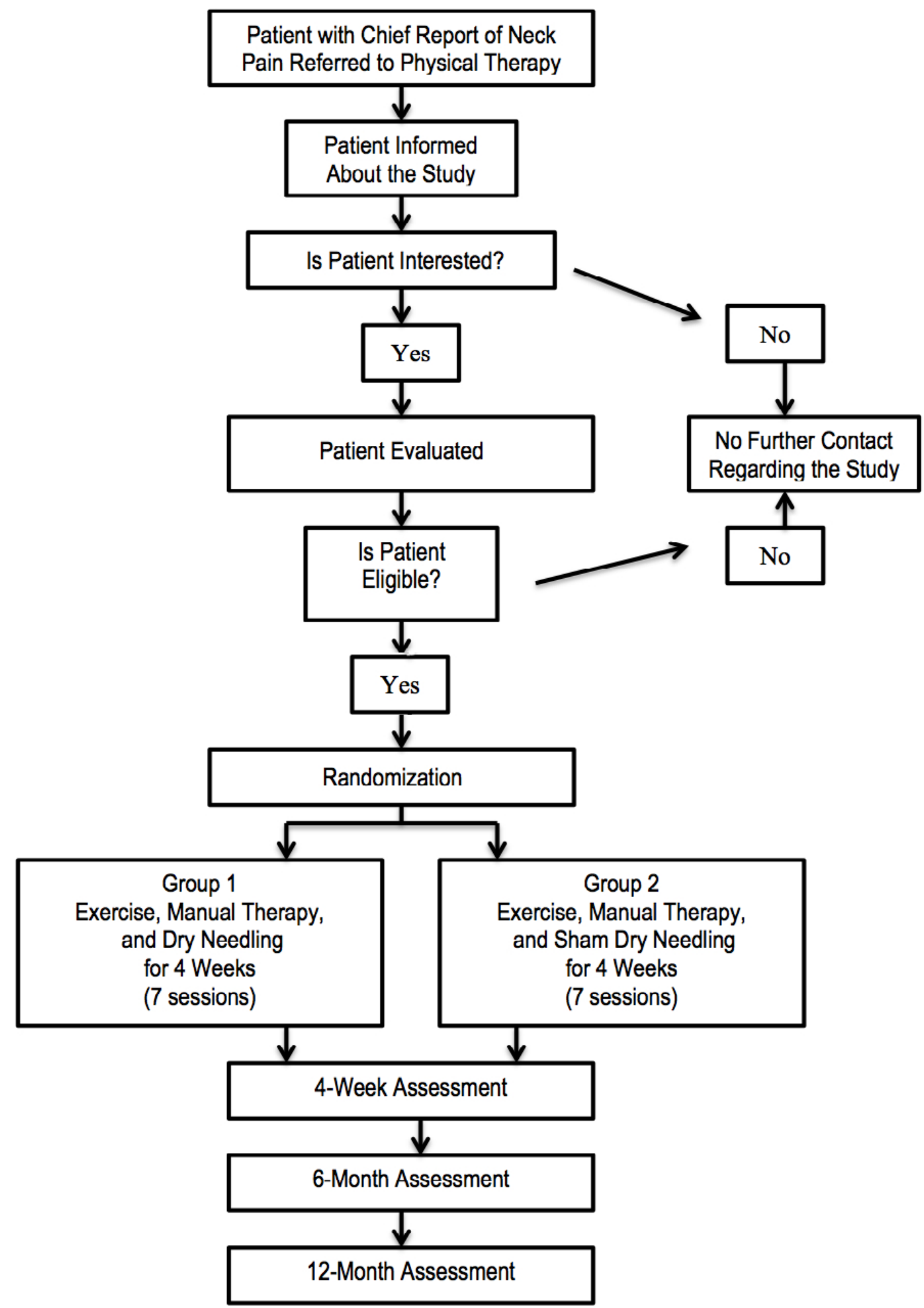




\section{Subjects}

Each physical therapy clinic, upon receiving a patient referral for neck pain, attempts to schedule the patient with the therapists who have agreed to assess and treat participants in the trial. Upon arrival for their initial assessments, patients are informed about the potential opportunity to participate in the study if they meet inclusion/exclusion criteria. A combination of physical examination and self-report measures will be used to assess each patient's potential eligibility to participate. Inclusion criteria for the study include the following: aged 18 years or older, a primary complaint of neck pain, and a Neck Disability Index (NDI) $>10$ points $=20 \%$ [44]. Patient exclusion criteria include the following: red flags (ie, tumor, fracture, metabolic diseases, rheumatoid arthritis, osteoporosis, prolonged history of steroid use, symptoms of vertebrobasilary insufficiency, pregnancy, cervical spinal stenosis, or bilateral upper extremity symptoms); use of blood thinners; history of whiplash injury within the past 6 weeks; evidence of central nervous system involvement, including hyperreflexia, sensory disturbances in the hand, intrinsic muscle wasting of the hands, unsteadiness during walking, nystagmus, loss of visual acuity, impaired sensation of the face, altered taste, or the presence of pathological reflexes such as positive Hoffman's and/or Babinski reflexes; two or more positive neurologic signs consistent with nerve root compression (ie, muscle weakness involving a major muscle group of the upper extremity, diminished upper extremity muscle stretch reflex, or diminished or absent sensation to pinprick in any upper extremity dermatome); prior surgery to the neck or thoracic spine; workers' compensation or pending legal action regarding their neck pain; insufficient English-language skills to complete all questionnaires; and inability to comply with treatment and follow-up schedule.

If a patient is determined to have met inclusion/exclusion criteria, they will be asked if they would like to participate in the study. If they choose to provide informed consent, each patient will complete the baseline questionnaires as well as the baseline outcome assessments. Demographic information will be collected for descriptive purposes, including age, gender, employment status, past medical history, mechanism of injury, location and nature of the patient's symptoms, number of days since onset, number of previous episodes of neck pain, and treatment for previous episodes. Once patients are admitted to the study, no patient will be removed from the study for noncompliance and an intention-to-treat analysis will be used.

\section{Outcome Measures}

\section{Overview}

All subjects will complete several commonly used instruments to assess their level of disability and neck pain. The primary outcome measure will be the NDI to capture the effect of treatment on the level of disability. Secondary outcome measures will include the Visual Analog Scale (VAS) to assess pain, the Global Rating of Change Scale (GROC) to measure the patient's perceived recovery, the patient perception of the intervention to determine if they felt they received the genuine dry needling intervention, and patient expectations to determine which treatments they believed would be most beneficial for their current condition. The self-report measures that will be used include those discussed in the following sections.

\section{Primary Outcome}

The NDI was created to measure pain-related disability associated with activities of daily living in people with neck pain $[45,46]$. The NDI contains 10 focused sections. Each item is scored on a 6-point scale and can reach a maximum score of 5; therefore, the maximum score is 50 . This score will be calculated as a percentage, with higher scores indicating higher levels of disability [46]. Content, construct validity, and reliability of the NDI has been previously shown in patients with neck pain $[46,47]$. The NDI has been used by researchers to evaluate the effect of treatments on patients' perceived levels of functioning and disability [48-51].

\section{Secondary Outcomes}

\section{Visual Analog Scale}

The VAS is a single-item measure of pain using a $100-\mathrm{mm}$ horizontal line anchored on the left side, which represents no pain, while the right side represents the worst pain imaginable. Patients mark a score by making a vertical line where they feel best represents their pain intensity. The VAS has been shown to be reliable [52] and valid [53].

\section{Patient Global Rating of Change}

The GROC will be used, which is a 15-point global rating scale described by Jaeschke et al [54]. The scale ranges from -7 ( $a$ very great deal worse) to zero (about the same) to +7 (a very great deal better). The global rating will be administered at the follow-up examinations only.

\section{Patient Perceptions}

Patient perceptions about the intervention will be used to determine whether the sham was an effective placebo. Patients will be asked for their perceptions on the dry needling intervention they received in order to determine if they felt they received genuine treatment. The following questions will be asked: What did you think of the dry needling intervention? Would you be willing to have the dry needling intervention again if you were attending physical therapy? Do you think you received the real dry needling intervention?

\section{Patient Expectations}

Patient expectations will be assessed at enrollment into the trial. Patients will be asked to rate each intervention on a 5-point Likert scale as to whether they believe each specific intervention will significantly help to improve this episode of their neck pain.

All outcome assessments will be performed by an individual blind to group assignment and will be performed at baseline, 4 weeks, 6 months, and 12 months. The latter two assessments will be mailed to the patients to improve return rate (see Table 1) [55]. 
Table 1. Summary of outcome measures and time points for collection.

\begin{tabular}{llll}
\hline Outcome measure & Baseline & 4 weeks & 6 months \\
\hline Neck Disability Index & Yes & Yes & Yes \\
Visual Analog Scale & Yes & Yes & Yes \\
Global Rating of Change & No & Yes & Yes \\
Patient perception of intervention & No & Yes & Yes \\
Patient expectations & Yes & No & No \\
\hline
\end{tabular}

\section{Intervention}

\section{Overview}

Once the baseline examination is complete, equal numbers of patients will be randomly assigned to one of two groups: (1) manual therapy, exercise, and dry needling (MTEX-Needle group) or (2) manual therapy, exercise, and sham dry needling (MTEX-Sham group). A random-number generator will be used to conduct the randomization. The randomization procedure will be conducted prior to the initiation of the study using a computer program randomizer by an individual not involved in patient recruitment. The randomization will be concealed according to the following procedure. The group assignment will be recorded on a label that will be placed inside an envelope and the envelope will be sealed. After the baseline examination is complete, the randomization envelope will be handed to a treating therapist and treatment will begin according to group assignment. Treatment will be initiated immediately following the baseline examination, unless prohibited by time constraints; in this case, the patient will be scheduled for a follow-up session within 3-5 days to receive the first treatment. Patients in both groups will attend physical therapy for seven treatments over a maximum of 4 weeks. Each treatment session will last for a total of 45 minutes of one-on-one treatment time with the treating physical therapist.

To ensure that the clinicians involved in administering the treatment are familiar with the procedures of the study, they will be required to participate in a 2-hour training session. During the training session, the manual therapy, exercise, and dry needling techniques will be reviewed to ensure treatments are applied in a standardized manner consistent with the treatment algorithm outlined below. The majority of the training time (ie, 1 hour) will be dedicated to ensuring standardization of the application of the dry needling and sham needling techniques. The second hour will be spent reviewing the manual therapy techniques, therapeutic exercises, and algorithms to help standardize their prescription, as well as data collection procedures. Due to the pragmatic nature of this study design, even when the treatment algorithm is followed for manual therapy and exercise, there will likely be some variation in the interventions selected by each therapist based on each patient's relevant examination findings. As this is a pragmatic trial designed to mimic usual clinical practice, this individualization of a patient's treatment is acceptable and expected. All therapists applying all interventions will be licensed physical therapists who have also completed the required postgraduate training that enables them by their state practice act to utilize dry needling, and who regularly use the technique in practice.

\section{Manual Therapy: 15 Minutes}

Individuals randomized to both groups will receive manual therapy to address joint mobility of the cervical and thoracic spine. Mobilization of the cervical spine and thrust manipulation targeting the thoracic spine will occur at the beginning of each treatment. The treatment algorithm, combined with physical examination findings, will guide clinicians to allow them to determine which techniques will be used and is outlined below (see Table 2).

\section{Physical Examination Techniques That Will Guide Manual Therapy Intervention}

\section{Cervical/Thoracic Spine Active Range of Motion and Behavior of Symptoms}

The examiner will record a single range of motion measurement for flexion and extension using an inclinometer as described by Hole [56]. Bilateral rotation will be measured using a standard long-arm goniometer [57]. Reliability coefficients for cervical spine range of motion parameters range from .81-.84 (inter-class correlation [ICC] 2,1) [56]. Thoracic rotation active range of motion will be assessed qualitatively. Patients will be asked to place their hands on opposite shoulders and to rotate the trunk. Care will be taken to maintain the cervical spine in neutral while the patient rotates the trunk to the left and right as far as possible. The behavior of symptoms and the presence of side-to-side asymmetry will be recorded.

\section{Spring Testing}

Spring testing of the cervical and thoracic spine over the spinous processes of the vertebrae will be tested with the patient prone $[58,59]$. The stiffness at each segment will be judged as normal, hypomobile, or hypermobile. Interpretation of whether a segment is hypomobile will be based on the examiner's anticipation of what normal mobility should feel like at that level and compared to the mobility detected in the segment above and below. In addition, pain provocation at each segment will be judged as painful or not painful and, if painful, whether the symptoms are local (ie, under the examiner's hand) or referred (ie, away from the examiner's hand). Spring testing for the neck will be performed over the spinous processes of C2-C7. Spring testing for the thoracic spine will be performed over the spinous processes of T1-T5. The reliability of spring testing from our previous work showed poor reliability in the cervical spine and fair-to-moderate reliability in the thoracic spine [60]. 
Table 2. Manual intervention algorithm for treatment selection.

\begin{tabular}{|c|c|}
\hline Assessment & Treatment \\
\hline \multirow[t]{2}{*}{$\begin{array}{l}\text { Clinicians assess cervical spine mobility and range } \\
\text { of motion, including overpressure and repeated } \\
\text { movements, if indicated }\end{array}$} & $\begin{array}{l}\text { If hypomobility or limited range of motion is identified in the cervical spine, the therapist will } \\
\text { utilize cervical thrust manipulation or nonthrust mobilizations; this may include central and unilat- } \\
\text { eral posterior-anterior, side glides, and occipito-atlanto joint }(\mathrm{C} 0-1)\end{array}$ \\
\hline & $\begin{array}{l}\text { Thrust manipulations may be repeated up to two times if reassessment of the patient shows im- } \\
\text { provements in range of motion, mobility, and/or pain }\end{array}$ \\
\hline \multirow[t]{4}{*}{$\begin{array}{l}\text { Clinicians assess thoracic spine mobility and range } \\
\text { of motion }\end{array}$} & $\begin{array}{l}\text { If hypomobility or limited range of motion is identified in the thoracic spine, the therapist will } \\
\text { utilize thoracic thrust manipulation and/or nonthrust manipulation (may include central and unilat- } \\
\text { eral posterior-anterior techniques to the thoracic spine and ribs) }\end{array}$ \\
\hline & $\begin{array}{l}\text { Thrust manipulation will be used unless contraindications noted (history or self-report of osteope- } \\
\text { nia/osteoporosis, etc) }\end{array}$ \\
\hline & $\begin{array}{l}\text { Thrust manipulations may be repeated up to two times if reassessment of the patient shows im- } \\
\text { provements in range of motion, mobility, and/or pain }\end{array}$ \\
\hline & $\begin{array}{l}\text { Nonthrust manipulations generally performed two to three times } \times 30 \text { repetitions at each hypomobile } \\
\text { level and may be repeated again (two to three times } \times 30 \text { repetitions) if the patient shows improve- } \\
\text { ments in range of motion, mobility, and/or pain }\end{array}$ \\
\hline
\end{tabular}

Table 3. Exercise intervention algorithm for treatment selection.

\begin{tabular}{ll}
\hline Assessment & Treatment \\
\hline $\begin{array}{l}\text { Muscular endurance of the cervical flexors was } \\
\text { evaluated with the deep neck flexor endurance } \\
\text { test and evaluated based on hold time in seconds }\end{array}$ & $\begin{array}{l}\text { Prepare participant in supine, hook-lying posi- } \\
\text { tion and ensure craniocervical and cervical re- } \\
\text { gions are in a neutral position (support with a } \\
\text { folded towel if necessary). }\end{array}$ \\
& $\begin{array}{l}\text { Teach the craniocervical flexion action. Use in- } \\
\text { structions of "feel the back of your head slide }\end{array}$ \\
& $\begin{array}{l}\text { up the bed as you nod your chin." } \\
\text { Goal: 10 } 10 \text { 10-second holds }\end{array}$ \\
& $\begin{array}{l}\text { Patient either prone on elbows or in four-point } \\
\text { kneeling position. } \\
\text { Craniocervical and cervical extensors }\end{array}$ \\
& $\begin{array}{l}\text { Suboccipital muscles-Focus on a neutral neck } \\
\text { position: (1) Require the participant to perform } \\
\text { craniocervical extension (chin down) and (2) } \\
\text { Require the participant to perform craniocervical } \\
\text { rotation (the saying "no" action). Assess quality } \\
\text { of movement and for smooth coordination. }\end{array}$ \\
Goal: 3 sets of 5
\end{tabular}

Progression

Begin with craniocervical flexion.

Cue patient to "keep chin tucked in, lift, and hold your head up."

Goal: $10 \times 10$-second holds

Patient either prone on elbows or in four-point kneeling position.

Deep cervical extensors: the craniocervical region remains in neutral and the axis of motion is now at C7. Instruct the participant to curl their neck first into flexion and then to curl their neck back to extension. The participant will often require manual facilitation to achieve the correct action. To assist in maintaining the craniocervical neutral position, let the participant imagine they have a book between their hands and they must keep their eyes on the book as they lift their head. Check that muscles such as splenius capitis are not overactive.

Goal: $10 \times 10$-second holds

Muscle length test: upper trapezius, latissimus dorsi, pectoralis minor, pectoralis major, levator scapulae, anterior and middle scalenes, and the suboccipital muscles; also scored as tight or normal

Manual muscle tests performed for the lower trapezius, rhomboids, middle trapezius, and serratus anterior
Stretching of muscles determined to have decreased length

Patient to perform $3 \times 30$-second stretches for each muscle

Goal: 3 sets of 30-second holds for each muscle

Patient to perform exercises without exacerbation of symptoms

Progressed based on patient response

All patients begin with thin elastic bands

Goal: 3 sets of 10
Self-overpressure to stretching of muscles will be added as appropriate

Patient will be progressed to medium, heavy, and extra heavy for resistance as appropriate, based on the patient's ability 


\section{Exercise: 15 Minutes}

Individuals randomized to both groups will receive exercise designed to improve performance of both the deep neck flexor musculature as well as the scapular musculature. The physical examination will guide exercise interventions. See the exercise intervention treatment algorithm in Table 3 [61]. Exercise will be performed after manual therapy and before dry needling. The goal of this program is to increase endurance and control of the muscles in the cervicothoracic region. The exercise portion will also include a stretching program targeting the cervicothoracic muscles, which have been placed in a shortened position as a result of poor postures. Patients will be instructed to perform the exercises as a home program twice daily. Each patient will be provided with a home exercise log that includes pictures as well as descriptions of all exercises. This exercise log will be used to encourage patient compliance.

The patient will be instructed to maintain usual activity levels within the limits of pain. Advice to maintain usual activity has been found to assist in recovery from neck pain. Patients will be instructed to do all activities that do not increase symptoms and to avoid activities that aggravate symptoms.

\section{Physical Examination Techniques That Will Guide Exercise Intervention}

\section{Neck Flexor Endurance}

Endurance of the neck flexors will be assessed with the patient lying supine in a hook-lying position. The patient will retract the chin and lift the head and neck until the head is approximately one inch above the plinth. Once in position, a line will be drawn across one of the skin folds along the patient's neck while the therapist maintains support just under the patient's occiput. When either the line edges begin to separate or if the patient's head touches the therapist's hand for more than one second, the test will be terminated. This technique has been demonstrated to have moderate reliability (ICC of .67) [62].

\section{Muscle Length Assessment}

Length of the upper trapezius, latissimus dorsi, pectoralis minor, pectoralis major, levator scapulae, anterior and middle scalenes, and the suboccipital muscles will be assessed according to the descriptions provided by Cleland et al [60]. Percent agreement between examiners in our previous work ranged from $77 \%$ to $85 \%$ [63].

\section{Muscle Strength Assessment}

Strength of the upper quadrant will be tested according to the techniques described by Kendall [64]. Percent agreement between examiners in our previous work ranged from $81 \%$ to $91 \%$ [63].

\section{Dry Needling: 15 Minutes}

Individuals randomized to the MTEX-Needle group will receive dry needling targeting the posterior musculature of the cervical and thoracic spine. Dry needling will occur after the manual therapy and exercise at each treatment session. The physical examination findings will guide clinicians to allow them to determine which specific muscles will be targeted (see Table
4). Examples of posterior muscles that can be treated include the trapezius, levator scapulae, splenius capitis, semispinalis, spinalis capitis, multifidi, and suboccipital muscles. The therapist will needle at least six sites up to a maximum of 10 based on identification of MTrPs. If six sites failed to be identified, the therapist will address as many sites that are present and document the number of sites treated. Once the needle has been inserted manually into the trigger point, the needle will be pistoned in an up-and-down fashion so that 2- to 3-mm vertical motions occur (ie, fast-in and fast-out technique as described by Hong) at approximately $1 \mathrm{~Hz}$ for $25-30$ seconds, with the aim of eliciting local twitch responses [65]. The maximum number of sessions of dry needling each participant will receive is six sessions, but therapists are instructed that if the patient has complete resolution of trigger points they do not need to continue with dry needling in subsequent sessions. The therapist also may discharge a patient at the therapist's and patient's discretion, as would normally be done in clinical practice.

\section{Physical Examination That Will Guide Dry Needling Intervention: Trigger Point Assessment}

The neck and upper quarter will be examined for the presence of the following: a hypersensitive spot in a palpable taut band, palpable or visible local twitch on pincer palpation, and reproduction of referred pain elicited by palpation of the sensitive spot. These criteria have been shown to exhibit good interexaminer reliability $(\kappa=.84-.88)$ when applied by an experienced clinician [66].

\section{Sham Dry Needling: 15 Minutes}

Park Sham acupuncture needles (AcuPrime) will be used to perform sham dry needling in all patients randomized to the MTEX-Sham group. These needles have been reported to be indistinguishable from real needles in a patient who has not experienced dry needling before [67]. The device consists of two plastic tubes that slide into one another and allow the blunted needle to cause a pricking sensation when pushed against the skin. This sham needle allows the patient to have the feeling that the needle is entering the skin while also maintaining therapist-patient contact time and treatment explanation. Sham dry needling is proposed to have less effect when compared to true dry needling [68]. Sham dry needling sites will be determined in the exact same fashion as in the MTEX-Needle group by the physical therapist after assessment. Therapists will be asked to sham needle at least six sites up to a maximum of 10, but the muscles that are (sham) treated will be left at the discretion of the physical therapist. The number of sites and specific muscles (sham) treated will be recorded by the therapist. Only posterior muscles of the cervical spine and upper thoracic spine, the same muscles targeted in the dry needling group, will be treated in order to ensure patients will be blinded to whether they received the real or sham needling.

\section{Data Analysis}

Descriptive statistics, including frequency counts for categorical variables and measures of central tendency and dispersion for continuous variables, will be calculated to summarize the data. 
Baseline demographic data will be compared across treatment

groups to assess the adequacy of the randomization.

Table 4. Dry needling intervention algorithm for treatment selection.

\begin{tabular}{|c|c|}
\hline Assessment & Treatment \\
\hline \multirow{3}{*}{$\begin{array}{l}\text { Trigger point assessment performed } \\
\text { on the trapezius }\end{array}$} & Patient in prone, therapist identifies the hypersensitive spot in the trapezius \\
\hline & The overlying skin will be cleansed with alcohol \\
\hline & $\begin{array}{l}\text { Once the needle has been inserted manually into the trigger point, the needle will be pistoned in an up-and-down } \\
\text { fashion so that } 2 \text { - to } 3 \text {-mm vertical motions occur (ie, fast-in and fast-out technique as described by Hong) at } \\
\text { approximately } 1 \mathrm{~Hz} \text { for } 25-30 \text { seconds, with the aim of eliciting local twitch responses }\end{array}$ \\
\hline
\end{tabular}

After needle is removed, pressure with a cotton ball will be maintained to prevent excessive bleeding

The number of sites and specific muscles treated will be recorded by the therapist

Trigger point assessment performed Patient in prone, therapist identifies the hypersensitive spot in the levator scapulae on the levator scapulae

The overlying skin will be cleansed with alcohol

Once the needle has been inserted manually into the trigger point, the needle will be pistoned in an up-and-down fashion so that 2- to 3-mm vertical motions occur (ie, fast-in and fast-out technique as described by Hong) at approximately $1 \mathrm{~Hz}$ for 25-30 seconds, with the aim of eliciting local twitch responses

After needle is removed, pressure with a cotton ball will be maintained to prevent excessive bleeding

The number of sites and specific muscles treated will be recorded by the therapist

Trigger point assessment performed Patient in prone, therapist identifies the hypersensitive spot in the splenius capitis, semispinalis, spinalis capitis, on the splenius capitis, semispinalis, or multifidi spinalis capitis, and multifidi

The overlying skin will be cleansed with alcohol

Once the needle has been inserted manually into the trigger point, the needle will be pistoned in an up-and-down fashion so that 2- to 3-mm vertical motions occur (ie, fast-in and fast-out technique as described by Hong) at approximately $1 \mathrm{~Hz}$ for 25-30 seconds, with the aim of eliciting local twitch responses

After needle is removed, pressure with a cotton ball will be maintained to prevent excessive bleeding

The number of sites and specific muscles treated will be recorded by the therapist

Trigger point assessment performed Patient in prone, therapist identifies the hypersensitive spot in the suboccipital muscles on the suboccipital muscles

The overlying skin will be cleansed with alcohol

Once the needle has been inserted manually into the trigger point, the needle will be pistoned in an up-and-down fashion so that 2- to 3-mm vertical motions occur (ie, fast-in and fast-out technique as described by Hong) at approximately $1 \mathrm{~Hz}$ for 25-30 seconds, with the aim of eliciting local twitch responses

After needle is removed, pressure with a cotton ball will be maintained to prevent excessive bleeding

The number of sites and specific muscles treated will be recorded by the therapist

We will compare baseline variables between groups by using independent $t$ tests or Mann-Whitney $\mathrm{U}$ tests for continuous data and chi-square tests of independence for categorical data. An intention-to-treat analysis will be utilized, in which all participants will be analyzed in the group to which they were originally assigned. All dropouts and the reasons for dropping out of the study will be reported. An a priori alpha level of .05 will be used for all analyses. All data will be checked to ensure they meet the assumptions for the inferential statistical analyses described below. If they do not meet the necessary assumptions, appropriate nonparametric procedures will be utilized. We will examine the primary aim with a two-way repeated-measures analysis of variance with treatment group (ie, manual therapy, exercise, and dry needling vs manual therapy, exercise, and sham dry needling) as the between-subjects independent variables and time (ie, baseline, 4 weeks, 6 months, and 12 months) as the within-subjects independent variable. The hypothesis of interest is the two-way group $\times$ time interaction.
Bonferroni-corrected post hoc tests will be used to determine difference between group means.

\section{Power Analysis}

Sample size and power calculations were performed using G*Power version 2 statistical software (Heinrich-HeineUniversität Düsseldorf) based on the minimal clinical improvement of 12 points on the NDI [51,69], assuming a standard deviation of 16 points, two-tailed, and an alpha level of .05. This requires a minimum sample size of 29 subjects per group. A total of 76 patients with a primary complaint of neck pain who meet the inclusion/exclusion criteria and consent to participate will be enrolled into the study. This sample size will yield greater than $80 \%$ power to detect both statistically significant and clinically meaningful changes in the NDI; additionally, this will control for dropouts prior to the 4-week follow-up. 


\section{Risks}

The risks associated with a patient's participation in this study are minimal. Patients may experience an increase in pain intensity from completing the range of motion exercise due to a muscle or ligament injury. Based on our clinical experience, the chance of this happening is rare, which means it occurs in less than $1 \%$ of people. We have attempted to minimize this risk by having a licensed physical therapist examine all patients and instruct them in the proper exercise technique. In addition, a therapist will re-examine a patient at any time, if appropriate. It is also possible that patients will experience mild muscle soreness after the manipulation is performed. Based on our clinical experience, the chance of this happening is common, which means it occurs in $1 \%-25 \%$ of people. However, this soreness typically resolves within 1-48 hours after manipulation. We have minimized the risks associated with manipulation by ensuring that the licensed physical therapists participating in this study already routinely use manipulation in the management of patients with neck pain. We have further minimized this risk by ensuring that each physical therapist participating in this study has been specifically trained in the use of the manipulation techniques to be used in this study. Furthermore, all potential subjects will be screened to ensure they do not exhibit any exclusion criteria that may place the individual at increased risk for a serious complication.

When dry needling treatment is performed, it is possible that patients will experience the following common adverse events: bruising, bleeding, pain during treatment, pain after treatment, or aggravation of symptoms $1.7 \%-7.6 \%$ of the time ( $2-8$ out of 100). Uncommon adverse events include the following: drowsiness, headache, or nausea $0.13 \%-0.26 \%$ of the time $(\sim 1-3$ out of 1000). Possible rare adverse events include fatigue, altered emotions, shaking, itching, claustrophobia, or numbness $0.01 \%-0.04 \%$ of the time (1-4 out of 10,000$)$. Dry needling is very safe; however, the most serious side effect from dry needling is pneumothorax (ie, lung collapse due to air inside the chest wall), which can occur in less than $0.01 \%$ ( $<1$ out of $10,000)$ treatments. This risk is very low and in a recent survey of physical therapists who use dry needling, Brady et al reported that no episodes of pneumothorax occurred in over 7600 treatments. We have minimized the risks associated with dry needling by ensuring that the licensed physical therapists participating in this study already routinely use dry needling in the management of patients with neck pain. We have further minimized this risk by ensuring that each physical therapist participating in this study has been specifically trained in the use of the dry needling techniques to be used in this study. Furthermore, all potential subjects will be screened to ensure they do not exhibit any exclusion criteria that may place the individual at increased risk for a serious complication.

Should any adverse event occur, it would be appropriately managed by the treating physical therapist by activating emergency services if immediate medical attention is required; standard clinical advice will be used in the case of minor events, such as transient soreness.

\section{Results}

This trial is registered at ClinicalTrials.gov (NCT02731014) and recruitment is currently underway and is expected to be completed by the end of 2017. Data collection for long-term outcomes will occur throughout 2017 and 2018. Data analysis, preparation, and publication submission is expected to occur throughout the final three quarters of 2018. See Table 5 for the study timeline and milestones.

Table 5. Timeline and milestones.

\begin{tabular}{|c|c|c|c|c|c|c|c|c|c|c|}
\hline \multirow[t]{2}{*}{ Activity } & \multicolumn{2}{|c|}{2016 (quarter) } & \multicolumn{3}{|c|}{2017 (quarter) } & \multicolumn{5}{|c|}{2018 (quarter) } \\
\hline & 3 & 4 & 1 & 2 & 3 & 4 & 1 & 2 & 3 & 4 \\
\hline Participant recruitment & $\mathrm{X}$ & $\mathrm{X}$ & $\mathrm{X}$ & $\mathrm{X}$ & $\mathrm{X}$ & $\mathrm{X}$ & & & & \\
\hline Data collection for long-term outcomes & & & $\mathrm{X}$ & $\mathrm{X}$ & $\mathrm{X}$ & $\mathrm{X}$ & $\mathrm{X}$ & $\mathrm{X}$ & $\mathrm{X}$ & $\mathrm{X}$ \\
\hline Data analysis, preparation, and submission for publication & & & & & & & & $\mathrm{X}$ & $\mathrm{X}$ & $\mathrm{X}$ \\
\hline Publication submissions & & & & & & & & & & $\mathrm{X}$ \\
\hline
\end{tabular}

\section{Discussion}

\section{Principle Findings}

Neck pain is commonly unresponsive or does not fully resolve with current treatment strategies, with $37 \%$ of patients going on to experience chronic neck pain of greater than one year [2]. Dry needling may be one intervention that could lead to improved outcomes when used in conjunction with exercise and manual therapy [11,39]. Anecdotally, in the clinical setting, a patient's pain level commonly limits their ability to participate in active exercise interventions. As dry needling appears to have a significant treatment effect on reducing pain and increasing pressure pain threshold [38], it may facilitate a patient's ability to perform a prescribed exercise program. In addition, it may improve patient compliance with exercise, which may lead to improved results from an exercise program.

Therefore, the aim of this trial is to determine if the addition of dry needling to an exercise and manual therapy treatment program will further reduce pain and improve disability in patients with mechanical neck pain, as compared to exercise and manual therapy and sham needling.

We hypothesize that patients who receive dry needling, manual therapy, and exercise will achieve greater reductions in pain and disability in the short term (ie, 4 weeks) and long term (ie, 6 and 12 months) compared to those who receive sham dry needling, manual therapy, and exercise. 
As the use of dry needling by physical therapists becomes more widespread, and more therapists are trained in this approach, research is needed to support or refute its effectiveness. The results of this trial will assist in providing long-term outcomes examining the effectiveness of dry needling, which are currently lacking in the literature.

We anticipate the potential challenges to this study to include the following: difficulty with patient recruitment, patient compliance with follow-up schedule, and patients lost to follow-up over the 1-year, long-term, follow-up period. To address these challenges, we have utilized two large clinics in different locations in the United States to improve the ability to recruit patients in a timely manner. Further, we will provide a small financial reimbursement for patients as incentive for completion of the 4-week, 6-month, and 12-month follow-up in order to assist with compliance and reduce the numbers lost to follow-up.

\section{Limitations}

We recognize that there are a number of potential limitations in the study design. The treating therapists cannot be blinded to group assignment, which may influence the verbal and nonverbal interaction with subjects. To try to manage this limitation, all therapists will be trained to maximize the consistency with which the dry needling intervention and the sham intervention will be performed.

We have chosen to allow therapists to perform individualized dry needling treatment specific to each patient within the outlined treatment algorithm to be consistent with clinical practice and improve external generalizability. We believe that providing treatment specific to the patient's presentation will improve outcomes. We understand this may be seen as a limitation as it may lead to variation in the treatments that will be applied by therapists, which may mask the difference between groups. However, individualized treatment better reflects clinical practice.

Another potential limitation is that we are not including physical measures such as range of motion or pain pressure threshold in our analyses. We have chosen to limit our outcomes to validated questionnaires in an effort to decrease loss to follow-up, especially at the long-term time points.

\section{Acknowledgments}

The authors would like to thank the Orthopaedic Section of the American Physical Therapy Association for providing funding for this trial.

\section{Conflicts of Interest}

None declared.

\section{Multimedia Appendix 1}

APTA Grant review peer review report.

[PDF File (Adobe PDF File), 564KB-Multimedia Appendix 1]

\section{Multimedia Appendix 2}

CONSORT - EHEALTH checklist (V.1.6.1).

\section{[PDF File (Adobe PDF File), 683KB-Multimedia Appendix 2]}

\section{References}

1. Hogg-Johnson S, van der Velde G, Carroll LJ, Holm LW, Cassidy JD, Guzman J, Bone and Joint Decade 2000-2010 Task Force on Neck Pain and Its Associated Disorders. The burden and determinants of neck pain in the general population: Results of the Bone and Joint Decade 2000-2010 Task Force on Neck Pain and Its Associated Disorders. Spine (Phila Pa 1976) 2008 Feb 15;33(4 Suppl):S39-S51. [doi: 10.1097/BRS.0b013e31816454c8] [Medline: 18204398]

2. Côté P, Cassidy JD, Carroll LJ, Kristman V. The annual incidence and course of neck pain in the general population: A population-based cohort study. Pain 2004 Dec;112(3):267-273. [doi: 10.1016/j.pain.2004.09.004] [Medline: 15561381]

3. Hoy D, March L, Woolf A, Blyth F, Brooks P, Smith E, et al. The global burden of neck pain: Estimates from the global burden of disease 2010 study. Ann Rheum Dis 2014 Jul;73(7):1309-1315. [doi: 10.1136/annrheumdis-2013-204431] [Medline: 24482302]

4. Martin BI, Deyo RA, Mirza SK, Turner JA, Comstock BA, Hollingworth W, et al. Expenditures and health status among adults with back and neck problems. JAMA 2008 Feb 13;299(6):656-664. [doi: 10.1001/jama.299.6.656] [Medline: $18270354]$

5. Jette AM, Smith K, Haley SM, Davis KD. Physical therapy episodes of care for patients with low back pain. Phys Ther 1994 Feb;74(2):101-110; discussion 110. [Medline: 8290616]

6. Swinkels ICS, Kooijman MK, Spreeuwenberg PM, Bossen D, Leemrijse CJ, van Dijk CE, et al. An overview of 5 years of patient self-referral for physical therapy in the Netherlands. Phys Ther 2014 Dec;94(12):1785-1795. [doi: 10.2522/ptj.20130309] [Medline: 25082921] 
7. Haines T, Gross AR, Burnie S, Goldsmith CH, Perry L, Graham N, Cervical Overview Group (COG). A Cochrane review of patient education for neck pain. Spine J 2009 Oct;9(10):859-871. [doi: 10.1016/j.spinee.2009.04.019] [Medline: 19596214]

8. Gross A, Kay TM, Paquin J, Blanchette S, Lalonde P, Christie T, Cervical Overview Group. Exercises for mechanical neck disorders. Cochrane Database Syst Rev 2015 Jan 28;1:CD004250. [doi: 10.1002/14651858.CD004250.pub5] [Medline: 25629215]

9. Gross AR, Kay T, Hondras M, Goldsmith C, Haines T, Peloso P, et al. Manual therapy for mechanical neck disorders: A systematic review. Man Ther 2002 Aug;7(3):131-149. [Medline: 12372310]

10. Patel KC, Gross A, Graham N, Goldsmith CH, Ezzo J, Morien A, et al. Massage for mechanical neck disorders. Cochrane Database Syst Rev 2012 Sep 12(9):CD004871. [doi: 10.1002/14651858.CD004871.pub4] [Medline: 22972078]

11. Gross AR, Hoving JL, Haines TA, Goldsmith CH, Kay T, Aker P, Cervical Overview Group. A Cochrane review of manipulation and mobilization for mechanical neck disorders. Spine (Phila Pa 1976) 2004 Jul 15;29(14):1541-1548. [Medline: $\underline{15247576}$ ]

12. Furlan AD, van Tulder M, Cherkin D, Tsukayama H, Lao L, Koes B, et al. Acupuncture and dry-needling for low back pain: An updated systematic review within the framework of the Cochrane Collaboration. Spine (Phila Pa 1976) 2005 Apr 15;30(8):944-963. [Medline: 15834340]

13. Ga H, Choi J, Park C, Yoon H. Dry needling of trigger points with and without paraspinal needling in myofascial pain syndromes in elderly patients. J Altern Complement Med 2007;13(6):617-624. [doi: 10.1089/acm.2006.6371] [Medline: $\underline{17718644]}$

14. Hsieh Y, Kao M, Kuan T, Chen S, Chen J, Hong C. Dry needling to a key myofascial trigger point may reduce the irritability of satellite MTrPs. Am J Phys Med Rehabil 2007 May;86(5):397-403. [doi: 10.1097/PHM.0b013e31804a554d] [Medline: 17449984]

15. Dommerholt J, Bron C, Franssen J. Myofascial trigger points: An evidence-informed review. J Man Manip Ther 2013 Jul 18;14(4):203-221. [doi: 10.1179/106698106790819991]

16. Dommerholt J, Grieve R, Layton M, Hooks T. An evidence-informed review of the current myofascial pain literature--January 2015. J Bodyw Mov Ther 2015 Jan;19(1):126-137. [doi: 10.1016/j.jbmt.2014.11.006] [Medline: 25603753]

17. Venâncio Rde A, Alencar FG, Zamperini C. Different substances and dry-needling injections in patients with myofascial pain and headaches. Cranio 2008 Apr;26(2):96-103. [doi: 10.1179/crn.2008.014] [Medline: 18468269]

18. Campa-Moran I, Rey-Gudin E, Fernández-Carnero J, Paris-Alemany A, Gil-Martinez A, Lerma LS, et al. Comparison of dry needling versus orthopedic manual therapy in patients with myofascial chronic neck pain: A single-blind, randomized pilot study. Pain Res Treat 2015;2015:327307 [FREE Full text] [doi: 10.1155/2015/327307] [Medline: 26640708]

19. Santos R, Carneiro M, Oliveira D, Maciel A, Monte-Silva K, Araújo M. Impact of dry needling and ischemic pressure in the myofascial syndrome: Controlled clinical trial. Fisioter Mov 2014 Dec;27(4):515-522. [doi: 10.1590/0103-5150.027.004.AO03]

20. Edwards J, Knowles N. Superficial dry needling and active stretching in the treatment of myofascial pain--A randomised controlled trial. Acupunct Med 2003 Sep;21(3):80-86 [FREE Full text] [Medline: 14620302]

21. Llamas-Ramos R, Pecos-Martín D, Gallego-Izquierdo T, Llamas-Ramos I, Plaza-Manzano G, Ortega-Santiago R, et al. Comparison of the short-term outcomes between trigger point dry needling and trigger point manual therapy for the management of chronic mechanical neck pain: A randomized clinical trial. J Orthop Sports Phys Ther 2014 Nov;44(11):852-861. [doi: 10.2519/jospt.2014.5229] [Medline: 25269764]

22. Mayoral O, Salvat I, Martín MT, Martín S, Santiago J, Cotarelo J, et al. Efficacy of myofascial trigger point dry needling in the prevention of pain after total knee arthroplasty: A randomized, double-blinded, placebo-controlled trial. Evid Based Complement Alternat Med 2013;2013:694941 [FREE Full text] [doi: 10.1155/2013/694941] [Medline: 23606888]

23. Mejuto-Vázquez MJ, Salom-Moreno J, Ortega-Santiago R, Truyols-Domínguez S, Fernández-de-Las-Peñas C. Short-term changes in neck pain, widespread pressure pain sensitivity, and cervical range of motion after the application of trigger point dry needling in patients with acute mechanical neck pain: A randomized clinical trial. J Orthop Sports Phys Ther 2014 Apr;44(4):252-260. [doi: 10.2519/jospt.2014.5108] [Medline: 24568260]

24. Pecos-Martín D, Montañez-Aguilera FJ, Gallego-Izquierdo T, Urraca-Gesto A, Gómez-Conesa A, Romero-Franco N, et al. Effectiveness of dry needling on the lower trapezius in patients with mechanical neck pain: A randomized controlled trial. Arch Phys Med Rehabil 2015 May;96(5):775-781. [doi: 10.1016/j.apmr.2014.12.016] [Medline: 25582412]

25. Pérez-Palomares S, Oliván-Blázquez B, Pérez-Palomares A, Gaspar-Calvo E, Pérez-Benito M, López-Lapeña E, et al. Contribution of dry needling to individualized physical therapy treatment of shoulder pain: A randomized clinical trial. J Orthop Sports Phys Ther 2017 Jan;47(1):11-20. [doi: 10.2519/jospt.2017.6698] [Medline: 27937046]

26. Pérez-Palomares S, Oliván-Blázquez B, Magallón-Botaya R, De-la-Torre-Beldarraín ML, Gaspar-Calvo E, Romo-Calvo L, et al. Percutaneous electrical nerve stimulation versus dry needling: Effectiveness in the treatment of chronic low back pain. J Musculoskelet Pain 2010 Mar 08;18(1):23-30. [doi: 10.3109/10582450903496047]

27. Salom-Moreno J, Ayuso-Casado B, Tamaral-Costa B, Sánchez-Milá Z, Fernández-de-Las-Peñas C, Alburquerque-Sendín F. Trigger point dry needling and proprioceptive exercises for the management of chronic ankle instability: A randomized clinical trial. Evid Based Complement Alternat Med 2015;2015:790209 [FREE Full text] [doi: 10.1155/2015/790209] [Medline: 26064172] 
28. Ziaeifar M, Arab AM, Karimi N, Nourbakhsh MR. The effect of dry needling on pain, pressure pain threshold and disability in patients with a myofascial trigger point in the upper trapezius muscle. J Bodyw Mov Ther 2014 Apr;18(2):298-305. [doi: 10.1016/j.jbmt.2013.11.004] [Medline: 24725800]

29. Alvarez DJ, Rockwell P. Trigger points: Diagnosis and management. Am Fam Physician 2002 Feb 15;65(4):653-660 [FREE Full text] [Medline: $\underline{11871683}$ ]

30. Hidalgo-Lozano A, Fernández-de-las-Peñas C, Calderón-Soto C, Domingo-Camara A, Madeleine P, Arroyo-Morales M. Elite swimmers with and without unilateral shoulder pain: Mechanical hyperalgesia and active/latent muscle trigger points in neck-shoulder muscles. Scand J Med Sci Sports 2013 Feb;23(1):66-73. [doi: 10.1111/j.1600-0838.2011.01331.x] [Medline: 21564310]

31. Hidalgo-Lozano A, Fernández-de-las-Peñas C, Díaz-Rodríguez L, González-Iglesias J, Palacios-Ceña D, Arroyo-Morales M. Changes in pain and pressure pain sensitivity after manual treatment of active trigger points in patients with unilateral shoulder impingement: A case series. J Bodyw Mov Ther 2011 Oct;15(4):399-404. [doi: 10.1016/j.jbmt.2010.12.003] [Medline: 21943613]

32. Castaldo M, Ge HY, Chiarotto A, Villafane JH, Arendt-Nielsen L. Myofascial trigger points in patients with whiplash-associated disorders and mechanical neck pain. Pain Med 2014 May;15(5):842-849. [doi: 10.1111/pme.12429] [Medline: 24641263]

33. Fernández-de-las-Peñas C, Alonso-Blanco C, Miangolarra JC. Myofascial trigger points in subjects presenting with mechanical neck pain: A blinded, controlled study. Man Ther 2007 Feb;12(1):29-33. [doi: 10.1016/j.math.2006.02.002] [Medline: 21882489]

34. Muñoz-Muñoz S, Muñoz-García MT, Alburquerque-Sendín F, Arroyo-Morales M, Fernández-de-las-Peñas C. Myofascial trigger points, pain, disability, and sleep quality in individuals with mechanical neck pain. J Manipulative Physiol Ther 2012 Oct;35(8):608-613. [doi: 10.1016/j.jmpt.2012.09.003] [Medline: 23158466]

35. Lucas N, Macaskill P, Irwig L, Moran R, Bogduk N. Reliability of physical examination for diagnosis of myofascial trigger points: A systematic review of the literature. Clin J Pain 2009 Jan;25(1):80-89. [doi: 10.1097/AJP.0b013e31817e13b6] [Medline: 19158550$]$

36. Cerezo-Téllez E, Torres-Lacomba M, Fuentes-Gallardo I, Perez-Muñoz M, Mayoral-Del-Moral O, Lluch-Girbés E, et al. Effectiveness of dry needling for chronic nonspecific neck pain: A randomized, single-blinded, clinical trial. Pain 2016 Sep;157(9):1905-1917. [doi: 10.1097/j.pain.0000000000000591] [Medline: 27537209]

37. Liu L, Huang Q, Liu Q, Ye G, Bo C, Chen M, et al. Effectiveness of dry needling for myofascial trigger points associated with neck and shoulder pain: A systematic review and meta-analysis. Arch Phys Med Rehabil 2015 May;96(5):944-955. [doi: 10.1016/j.apmr.2014.12.015] [Medline: 25576642]

38. Gattie E, Cleland JA, Snodgrass S. The effectiveness of trigger point dry needling for musculoskeletal conditions by physical therapists: A systematic review and meta-analysis. J Orthop Sports Phys Ther 2017 Mar;47(3):133-149. [doi: 10.2519/jospt.2017.7096] [Medline: 28158962]

39. Liu L, Huang QM, Liu QG, Thitham N, Li LH, Ma YT, et al. Evidence for dry needling in the management of myofascial trigger points associated with low back pain: A systematic review and meta-analysis. Arch Phys Med Rehabil 2017 Jul 08. [doi: 10.1016/j.apmr.2017.06.008] [Medline: 28690077]

40. Nygren A, Berglund A, von Koch M. Neck-and-shoulder pain, an increasing problem. Strategies for using insurance material to follow trends. Scand J Rehabil Med Suppl 1995;32:107-112. [Medline: 7784832]

41. Seffinger MA, Najm WI, Mishra SI, Adams A, Dickerson VM, Murphy LS, et al. Reliability of spinal palpation for diagnosis of back and neck pain: A systematic review of the literature. Spine (Phila Pa 1976) 2004 Oct 01;29(19):E413-E425. [Medline: 15454722]

42. Eysenbach G, CONSORT-EHEALTH Group. CONSORT-EHEALTH: Improving and standardizing evaluation reports of Web-based and mobile health interventions. J Med Internet Res 2011;13(4):e126 [FREE Full text] [doi: 10.2196/jmir.1923] [Medline: 22209829]

43. Schulz KF, Altman DG, Moher D. CONSORT 2010 Statement: Updated guidelines for reporting parallel group randomised trials. Trials 2010 Mar 24;11:32 [FREE Full text] [doi: 10.1186/1745-6215-11-32] [Medline: 20334632]

44. Cleland JA, Mintken PE, Carpenter K, Fritz JM, Glynn P, Whitman J, et al. Examination of a clinical prediction rule to identify patients with neck pain likely to benefit from thoracic spine thrust manipulation and a general cervical range of motion exercise: Multi-center randomized clinical trial. Phys Ther 2010 Sep;90(9):1239-1250. [doi: 10.2522/ptj.20100123] [Medline: 20634268]

45. Childs JD, Cleland JA, Elliott JM, Teyhen DS, Wainner RS, Whitman JM, et al. Neck pain: Clinical practice guidelines linked to the International Classification of Functioning, Disability, and Health from the Orthopedic Section of the American Physical Therapy Association. J Orthop Sports Phys Ther 2008 Sep;38(9):A1-A34. [doi: 10.2519/jospt.2008.0303] [Medline: 18758050]

46. Vernon H, Mior S. The Neck Disability Index: A study of reliability and validity. J Manipulative Physiol Ther 1991 Sep;14(7):409-415. [Medline: 1834753] 
47. Hoving JL, O'Leary EF, Niere KR, Green S, Buchbinder R. Validity of the neck disability index, Northwick Park neck pain questionnaire, and problem elicitation technique for measuring disability associated with whiplash-associated disorders. Pain 2003 Apr;102(3):273-281. [Medline: $\underline{\text { 12670669] }] ~}$

48. Cleland JA, Childs JD, McRae M, Palmer JA, Stowell T. Immediate effects of thoracic manipulation in patients with neck pain: A randomized clinical trial. Man Ther 2005 May;10(2):127-135. [doi: 10.1016/j.math.2004.08.005] [Medline: 15922233]

49. Tseng Y, Wang WTJ, Chen W, Hou T, Chen T, Lieu F. Predictors for the immediate responders to cervical manipulation in patients with neck pain. Man Ther 2006 Nov;11(4):306-315. [doi: 10.1016/j.math.2005.08.009] [Medline: 16380287]

50. Riddle DL, Stratford PW. Use of generic versus region-specific functional status measures on patients with cervical spine disorders. Phys Ther 1998 Sep;78(9):951-963. [Medline: 9736893]

51. Cleland JA, Fritz JM, Whitman JM, Palmer JA. The reliability and construct validity of the Neck Disability Index and patient specific functional scale in patients with cervical radiculopathy. Spine (Phila Pa 1976) 2006 Mar 01;31(5):598-602. [doi: 10.1097/01.brs.0000201241.90914.22] [Medline: 16508559]

52. Bijur PE, Silver W, Gallagher EJ. Reliability of the visual analog scale for measurement of acute pain. Acad Emerg Med 2001 Dec;8(12):1153-1157. [Medline: 11733293 ]

53. Crossley KM, Bennell KL, Cowan SM, Green S. Analysis of outcome measures for persons with patellofemoral pain: Which are reliable and valid? Arch Phys Med Rehabil 2004 May;85(5):815-822. [Medline: 15129407]

54. Jaeschke R, Singer J, Guyatt GH. Measurement of health status. Ascertaining the minimal clinically important difference. Control Clin Trials 1989 Dec;10(4):407-415. [Medline: 2691207]

55. Leece P, Bhandari M, Sprague S, Swiontkowski MF, Schemitsch EH, Tornetta P, et al. Internet versus mailed questionnaires: A controlled comparison (2). J Med Internet Res 2004 Oct 29;6(4):e39 [FREE Full text] [doi: 10.2196/jmir.6.4.e39] [Medline: 15631963]

56. Hole DE, Cook JM, Bolton JE. Reliability and concurrent validity of two instruments for measuring cervical range of motion: Effects of age and gender. Man Ther 1995 Nov;1(1):36-42. [doi: 10.1054/math.1995.0248] [Medline: 11327793]

57. Youdas JW, Carey JR, Garrett TR. Reliability of measurements of cervical spine range of motion--Comparison of three methods. Phys Ther 1991 Feb;71(2):98-104; discussion 105. [Medline: 1989013]

58. Maher CG, Latimer J, Adams R. An investigation of the reliability and validity of posteroanterior spinal stiffness judgments made using a reference-based protocol. Phys Ther 1998 Aug;78(8):829-837. [Medline: 9711208]

59. Smedmark V, Wallin M, Arvidsson I. Inter-examiner reliability in assessing passive intervertebral motion of the cervical spine. Man Ther 2000 May;5(2):97-101. [doi: 10.1054/math.2000.0234] [Medline: 10903585]

60. Cleland JA, Childs JD, Fritz JM, Whitman JM. Interrater reliability of the history and physical examination in patients with mechanical neck pain. Arch Phys Med Rehabil 2006 Oct;87(10):1388-1395. [doi: 10.1016/j.apmr.2006.06.011] [Medline: 17023251]

61. Michaleff ZA, Maher CG, Lin CW, Rebbeck T, Jull G, Latimer J, et al. Comprehensive physiotherapy exercise programme or advice for chronic whiplash (PROMISE): A pragmatic randomised controlled trial. Lancet 2014 Jul 12;384(9938):133-141. [doi: 10.1016/S0140-6736(14)60457-8] [Medline: 24703832]

62. Harris KD, Heer DM, Roy TC, Santos DM, Whitman JM, Wainner RS. Reliability of a measurement of neck flexor muscle endurance. Phys Ther 2005 Dec;85(12):1349-1355. [Medline: 16305273]

63. Cleland JA, Childs JD, Fritz JM, Whitman JM, Eberhart SL. Development of a clinical prediction rule for guiding treatment of a subgroup of patients with neck pain: Use of thoracic spine manipulation, exercise, and patient education. Phys Ther 2007 Jan;87(1):9-23. [doi: 10.2522/ptj.20060155] [Medline: 17142640]

64. Peterson Kendall F, Kendall McCreary E, Geise Provance P, McIntyre Rodgers M, Anthony Romani W. Muscles: Testing and Function With Posture and Pain. 5th edition. Baltimore, MD: Lippincott Williams \& Wilkins; 2005.

65. Hong CZ. Lidocaine injection versus dry needling to myofascial trigger point. The importance of the local twitch response. Am J Phys Med Rehabil 1994;73(4):256-263. [Medline: 8043247]

66. Gerwin RD, Shannon S, Hong CZ, Hubbard D, Gevirtz R. Interrater reliability in myofascial trigger point examination. Pain 1997 Jan;69(1-2):65-73. [Medline: 9060014]

67. Park J, White A, Stevinson C, Ernst E, James M. Validating a new non-penetrating sham acupuncture device: Two randomised controlled trials. Acupunct Med 2002 Dec;20(4):168-174 [FREE Full text] [Medline: 12512790]

68. White P, Lewith G, Hopwood V, Prescott P. The placebo needle, is it a valid and convincing placebo for use in acupuncture trials? A randomised, single-blind, cross-over pilot trial. Pain 2003 Dec;106(3):401-409. [Medline: 14659523]

69. Cleland JA, Childs JD, Whitman JM. Psychometric properties of the Neck Disability Index and Numeric Pain Rating Scale in patients with mechanical neck pain. Arch Phys Med Rehabil 2008 Jan;89(1):69-74. [doi: 10.1016/j.apmr.2007.08.126] [Medline: 18164333]

\section{Abbreviations \\ GROC: Global Rating of Change Scale \\ ICC: inter-class correlation}


MTEX-Needle: manual therapy, exercise, and dry needling

MTEX-Sham: manual therapy, exercise, and sham dry needling

MTrP: myofascial trigger point

NDI: Neck Disability Index

VAS: Visual Analog Scale

Edited by G Eysenbach; submitted 29.05.17; peer-reviewed by D Clewley, D Bossen, P Santaguida; comments to author 12.07.17;

revised version received 21.08.17; accepted 21.08.17; published 22.11.17

Please cite as:

Gattie ER, Cleland JA, Snodgrass SJ

Dry Needling for Patients With Neck Pain: Protocol of a Randomized Clinical Trial

JMIR Res Protoc 2017;6(11):e227

URL: http://www.researchprotocols.org/2017/11/e227/

doi: $10.2196 /$ resprot.7980

PMID: 29167092

CEric Robert Gattie, Joshua A Cleland, Suzanne J Snodgrass. Originally published in JMIR Research Protocols (http://www.researchprotocols.org), 22.11.2017. This is an open-access article distributed under the terms of the Creative Commons Attribution License (https://creativecommons.org/licenses/by/4.0/), which permits unrestricted use, distribution, and reproduction in any medium, provided the original work, first published in JMIR Research Protocols, is properly cited. The complete bibliographic information, a link to the original publication on http://www.researchprotocols.org, as well as this copyright and license information must be included. 